\title{
Anion Conductive Aromatic Copolymers from Dimethylaminomethylated Monomers: Synthesis, Properties and Applications in Alkaline Fuel Cells
}

\author{
Ryo Akiyama, ${ }^{\dagger}$ Naoki Yokota ${ }^{\S}$ Eriko Nishino, ${ }^{\|}$Koichiro Asazawa, ${ }^{\|}$and Kenji Miyatake* ${ }^{\dagger}, \ddagger$
}

${ }^{\dagger}$ Fuel Cell Nanomaterials Center, and ${ }^{\star}$ Clean Energy Research Center, University of Yamanashi, 4 Takeda, Kofu 400-8510, Japan

$\S$ Takahata Precision Japan Co. Ltd., 390 Maemada, Sakaigawa, Fuefuki, Yamanashi, 406-0843, Japan

" Frontier Technology R\&D Division, Daihatsu Motor Co. Ltd., 3000 Ryuo, Gamo, Shiga 520-2593, Japan

*Corresponding Author

E-mail miyatake@yamanashi.ac.jp; Tel +81 552208707; Fax +81 552208707 (KM). 
General Method. ${ }^{1} \mathrm{H}$ NMR spectra were recorded on a JEOL JNM-ECA 500 (500 MHz) using $\mathrm{CDCl}_{3}$, TCE- $d_{2}$ or DMSO- $d_{6}$ as a solvent and tetramethylsilane (TMS) as an internal reference. Chemical shifts are reported in ppm with TMS as the internal reference $(\delta 0.0)$. Data are reported as follows: chemical shift, multiplicity $(\mathrm{s}=$ singlet, $\mathrm{d}=$ doublet, $\mathrm{t}=$ triplet, $\mathrm{q}=$ quartet, $\mathrm{m}=$ multiplet, $\mathrm{br}=$ broad $)$, coupling constants $(\mathrm{Hz})$ and integration . ${ }^{13} \mathrm{C}$ NMR spectra were recorded on a JEOL JNM-ECA $500(125 \mathrm{MHz})$ using $\mathrm{CDCl}_{3}$ with complete proton decoupling. Chemical sift were recorded in ppm with the solvent references as the internal standard $\left(\mathrm{CDCl}_{3}: \delta\right.$ 77.0). Gel permeation chromatography (GPC) was performed on a JASCO intelligent HPLC pump PU-2080 (flow rate $=0.5 \mathrm{~mL} \mathrm{~min}^{-1}$ ) coupled with a photodiode array detector MD-2018, a column oven CO-2065 and a column Shodex SB-803HQ. GPC for polymers was performed on a JASCO intelligent HPLC pump PU-2080 (flow rate =

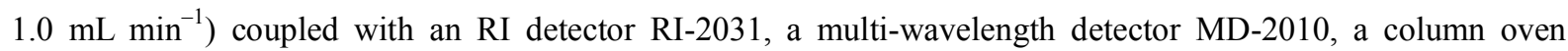
CO-965, and a column Shodex K-805L. In both measurements, DMF containing 0.01 M lithium bromide was used as eluent and column temperature was set at $50{ }^{\circ} \mathrm{C}$. Molecular weight was calibrated with standard polystyrene samples. For transition electron microscopic (TEM) observation, the membranes were stained with tetrachloroplatinate ions by ion exchange of the ammonium groups in $0.5 \mathrm{M}$ potassium tetrachloroplatinate (II) aqueous solution at $40{ }^{\circ} \mathrm{C}$ for $48 \mathrm{~h}$, rinsed with deionized water, and dried at $60{ }^{\circ} \mathrm{C}$ under reduced pressure overnight. The stained membranes were embedded in epoxy resin, sectioned to $50 \mathrm{~nm}$ thickness with a Leica microtome Ultracut UCT, and placed on a copper grid. Images were taken on a Hitachi H-9500 TEM with an accelerating voltage of $200 \mathrm{kV}$. Hydroxide ion conductivity of the membranes was measured in degassed, deionized water using a four-probe conductivity cell attached to an AC impedance spectroscopy system (Solartron 1255B and 1287). Dynamic mechanical analysis (DMA) was carried out with as ITK DVA-225 dynamic viscoelastic analyzer.

All commercially available reagents were used as received for the reactions without any purification. For TLC analysis, Merk precoated TLC aluminum sheets (silica gel $60 \mathrm{~F}_{254}$ ) were used. For preparative column chromatography, Kanto Chemical Co., Inc. silica gel 60 N (spherical neutral, particle size 100-210 $\mu \mathrm{m}$ ) was used. 
Synthesis of dichloromonomer 3. Synthetic compounds were well-characterized by ${ }^{1} \mathrm{H}$ NMR and ${ }^{13} \mathrm{C}$ NMR spectra (Figures S1-S6).
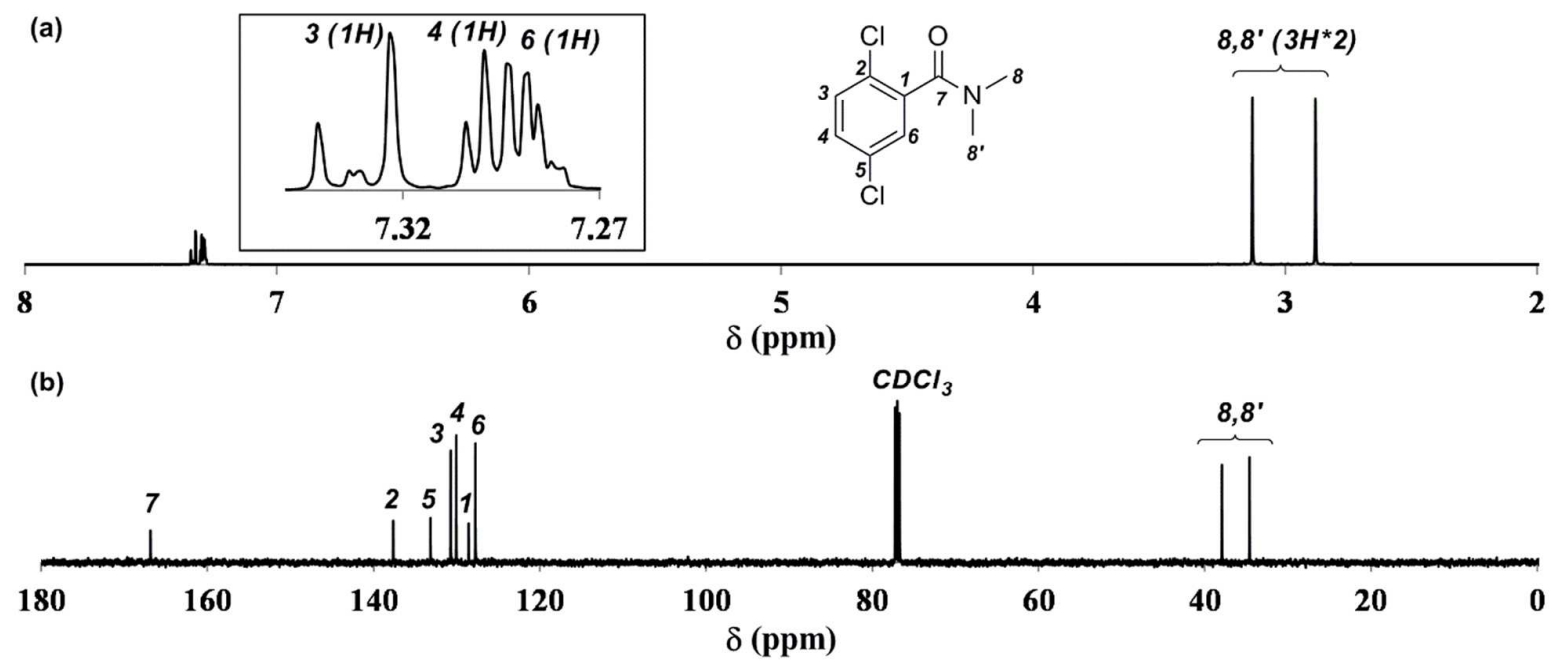

Figure S1. (a) ${ }^{1} \mathrm{H}$ and (b) ${ }^{13} \mathrm{C}$ NMR spectra of 2,5-dichloro- $N, N$-dimethylbenzamide (2a) in $\mathrm{CDCl}_{3}$

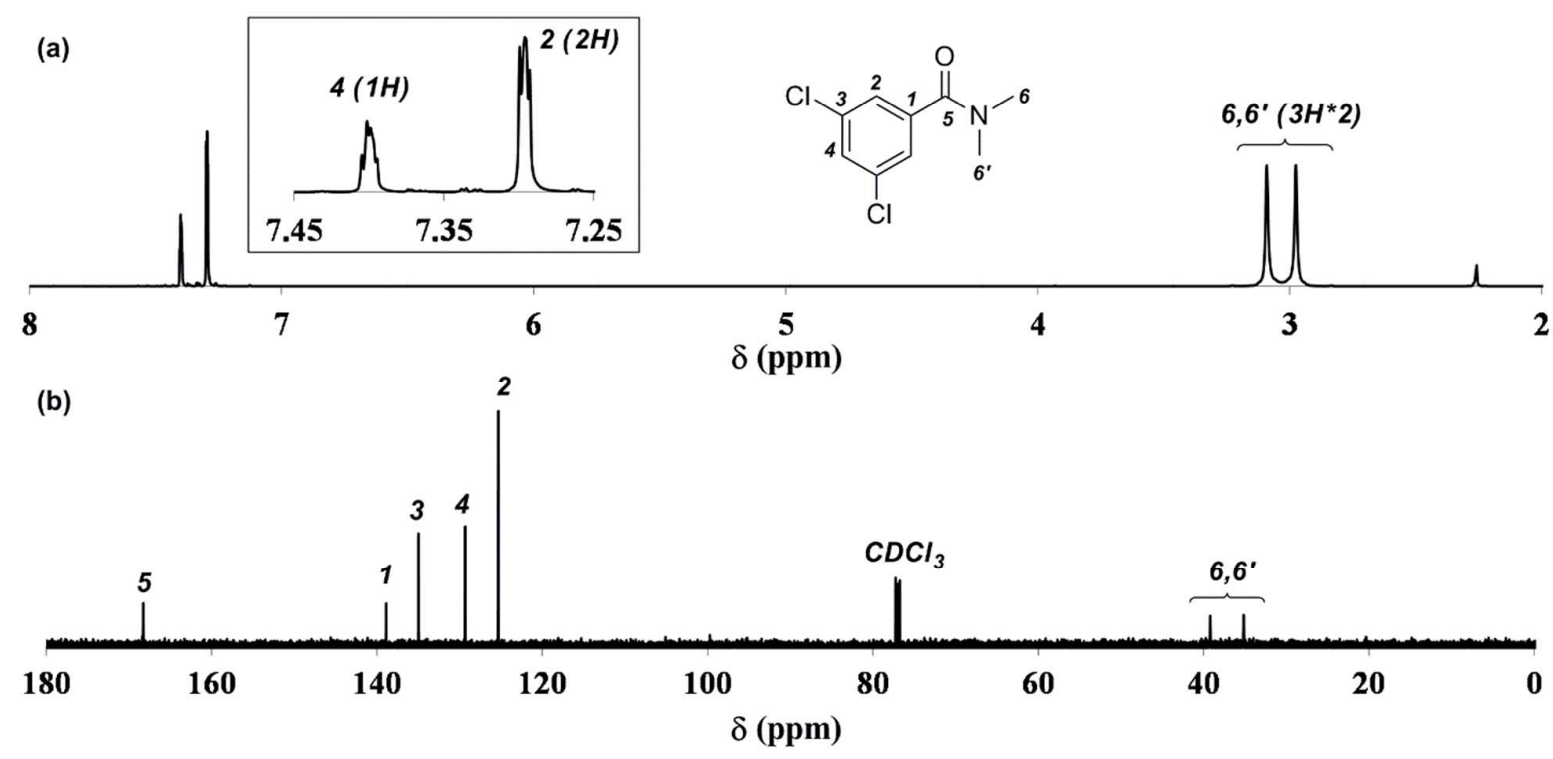

Figure S2. (a) ${ }^{1} \mathrm{H}$ and (b) ${ }^{13} \mathrm{C}$ NMR spectra of 3,5-dichloro- $N, N$-dimethylbenzamide (2b) in $\mathrm{CDCl}_{3}$ 

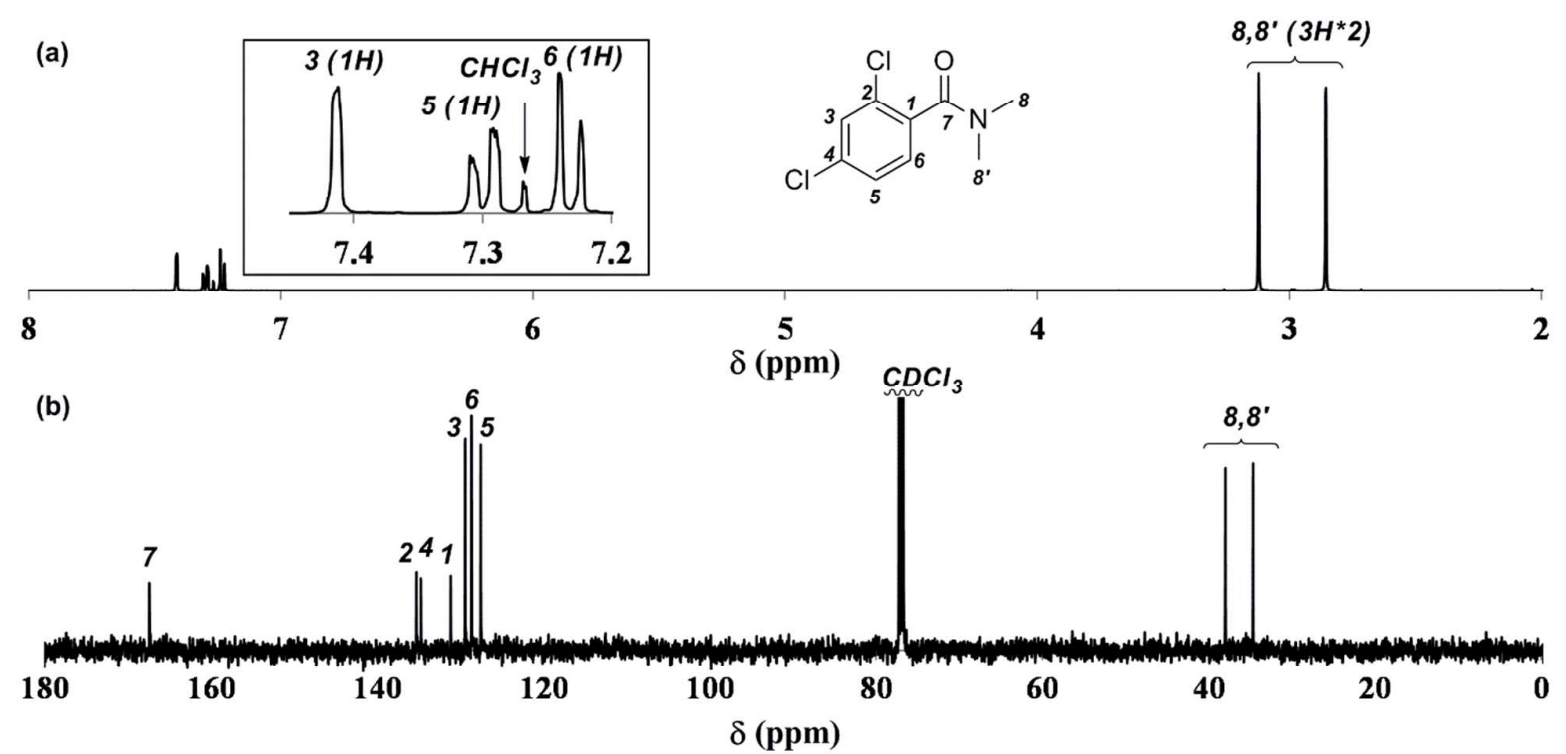

Figure S3. (a) ${ }^{1} \mathrm{H}$ and (b) ${ }^{13} \mathrm{C}$ NMR spectra of 2,4-dichloro- $N, N$-dimethylbenzylamine (2c) in $\mathrm{CDCl}_{3}$

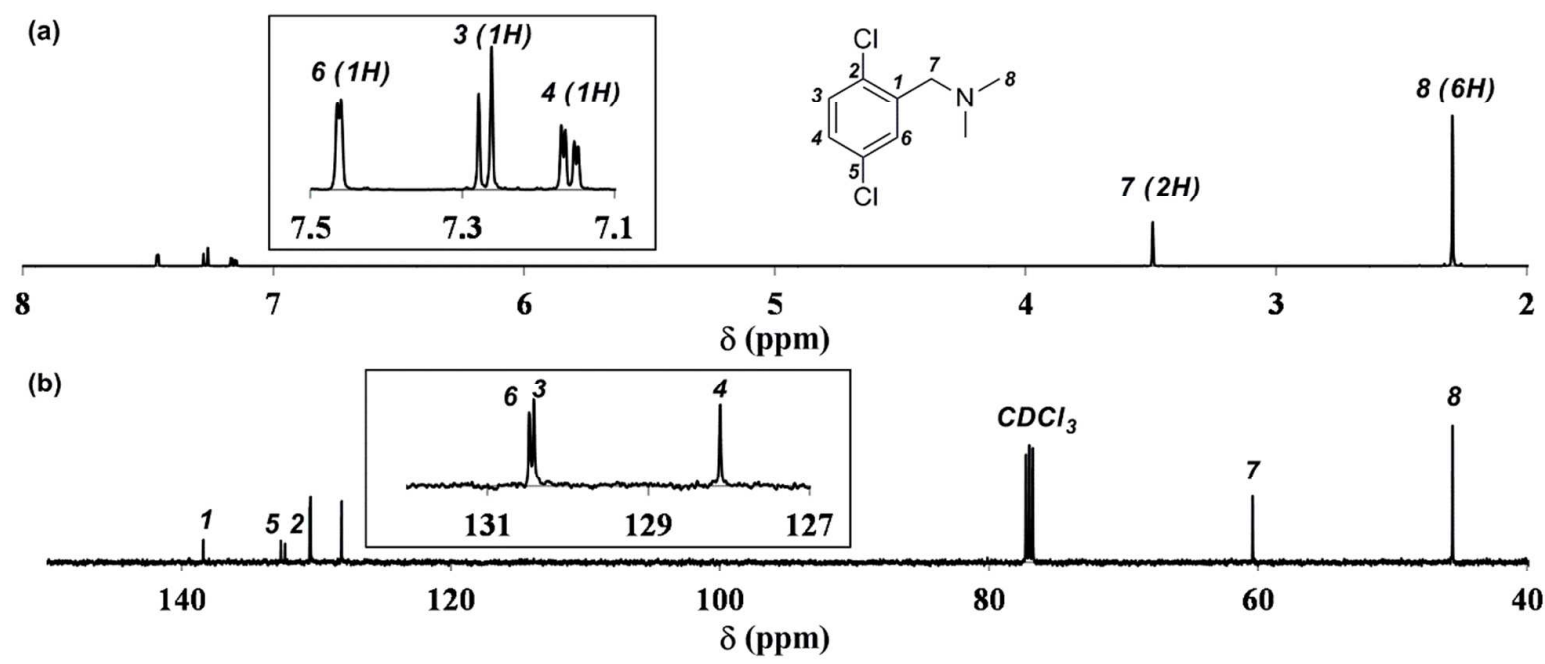

Figure S4. (a) ${ }^{1} \mathrm{H}$ and (b) ${ }^{13} \mathrm{C}$ NMR spectra of 2,5-dichloro- $N, N$-dimethylbenzylamine (3a) in $\mathrm{CDCl}_{3}$ 


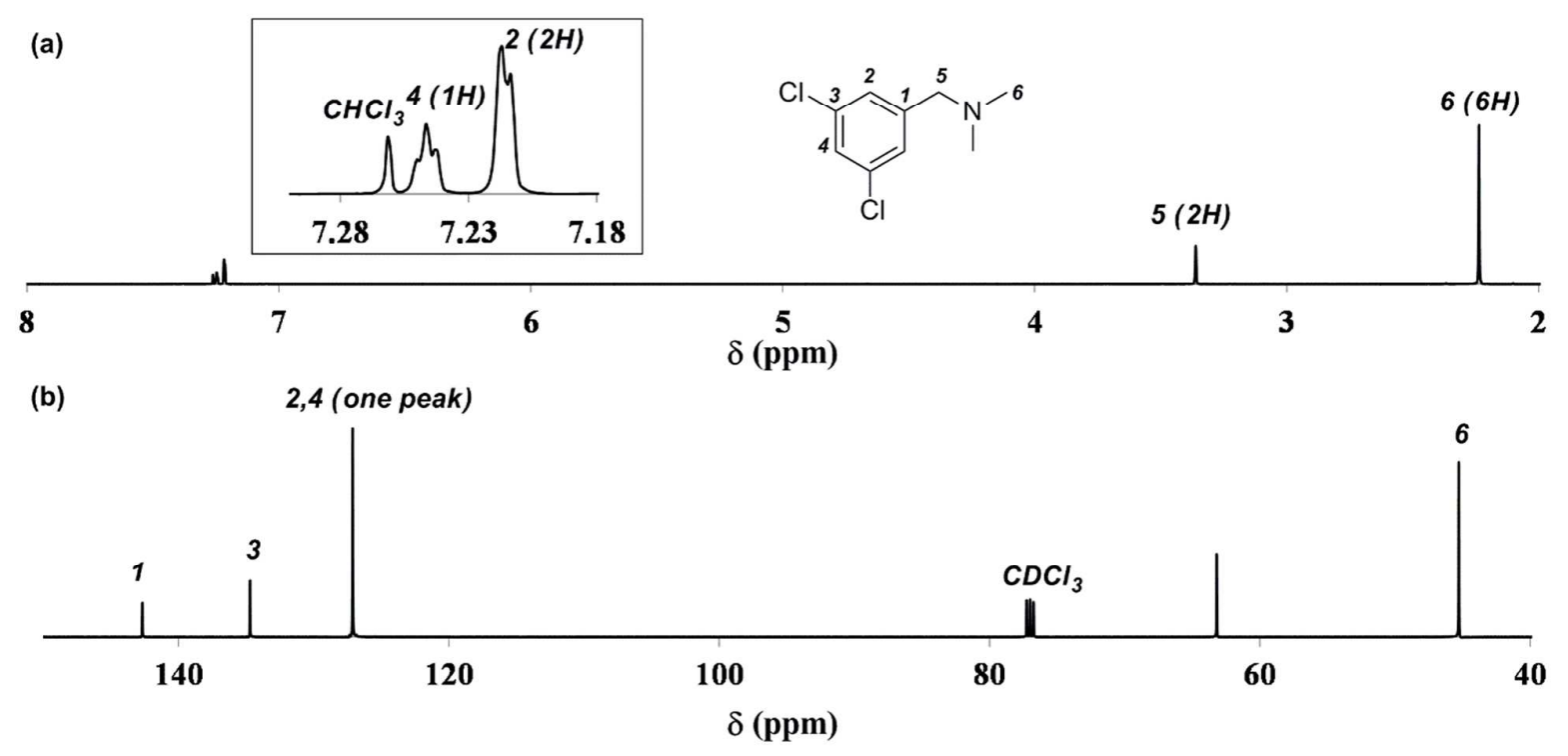

Figure S5. (a) ${ }^{1} \mathrm{H}$ and (b) ${ }^{13} \mathrm{C}$ NMR spectra of 3,5-dichloro- $N, N$-dimethylbenzylamine (3b) in $\mathrm{CDCl}_{3}$

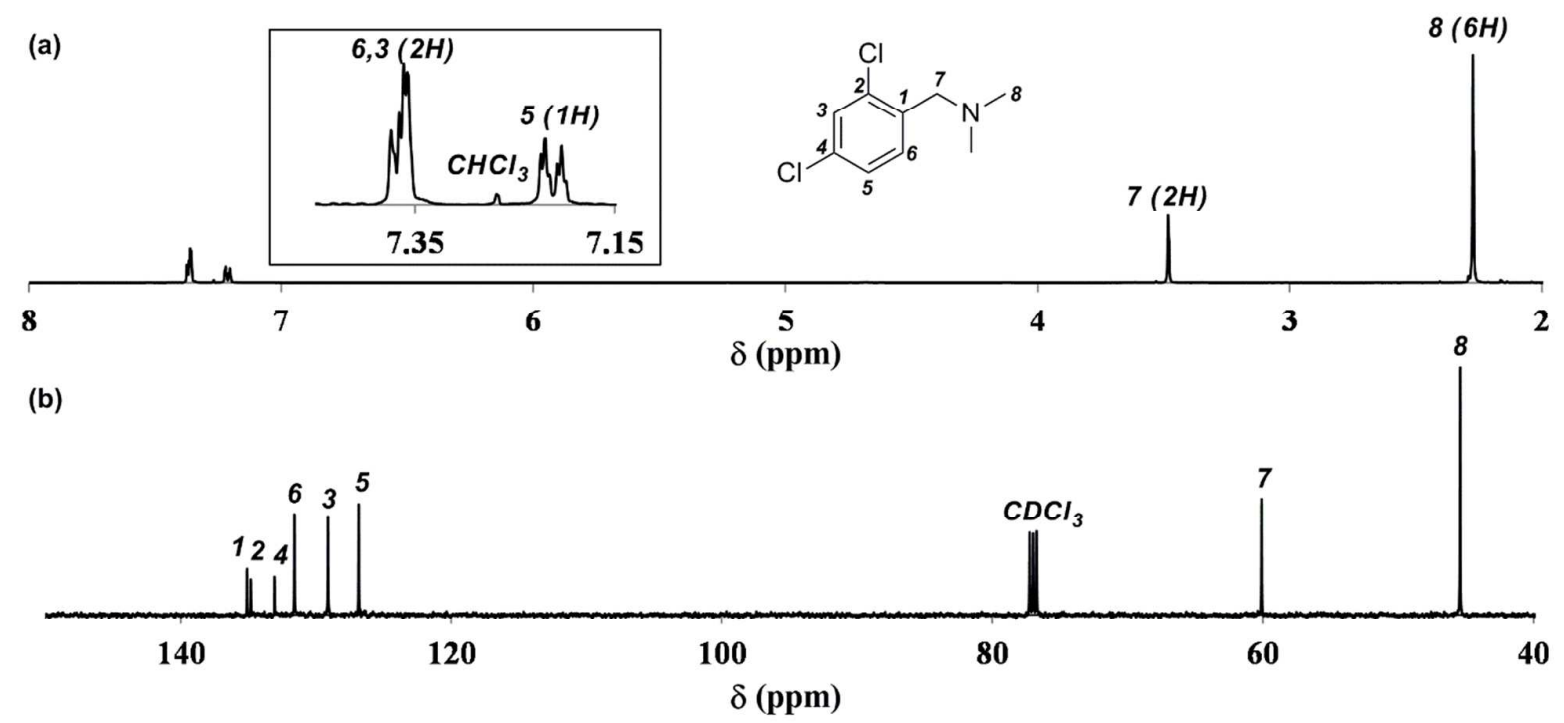

Figure S6. (a) ${ }^{1} \mathrm{H}$ and (b) ${ }^{13} \mathrm{C}$ NMR spectra of 2,4-dichloro- $N, N$-dimethylbenzylamine (3c) in $\mathrm{CDCl}_{3}$

Synthesis of CIPS-terminated telechelic hydrophobic oligomers 4. A typical procedure is as follows $(X$ =4). A $500 \mathrm{~mL}$ three neck round-bottomed flask equipped with a Dean-Stark trap, a condenser, a nitrogen purge and a magnetic stirrer bar was charged with ClPS (16.0 g, $55.6 \mathrm{mmol})$, DHBP (9.52 g, $44.4 \mathrm{mmol})$, potassium carbonate $(15.4 \mathrm{~g}, 111 \mathrm{mmol}), \mathrm{DMAc}(140 \mathrm{~mL})$ and toluene $(48 \mathrm{~mL})$. After stirring at $170{ }^{\circ} \mathrm{C}$ for $4 \mathrm{~h}$, toluene was removed. Then, after $27 \mathrm{~h}$, additional CIPS (1.60 g, $5.57 \mathrm{mmol})$ as an end-capping reagent was added 
to the mixture. After further $1 \mathrm{~h}$, the reaction mixture was cooled to room temperature and poured into a $1 \mathrm{~L}$ of deionized water to afford the light brown precipitate. The resulting solid was collected by filtration, washed with hot deionized water and hot methanol several times and dried at $80^{\circ} \mathrm{C}$ under reduced pressure overnight to afford desired oligomer 4 (20.9 g, 94\% yield). $\quad{ }^{1} \mathrm{H}$ NMR spectrum and GPC profile of obtained oligomer were shown in Figure 1a and Figure S8. The degrees of the oligomerization were determined to be $X=5.1$ from ${ }^{1} \mathrm{H}$ NMR and $X$ $=7.1$ from GPC, respectively.

Oligomers 4 which had different chain length were also synthesized in a same procedure mentioned above. The results of the oligomerization $(X=2$ and 8$)$ are summarized in Table $1 .{ }^{1} \mathrm{H}$ NMR spectra and GPC profiles of the obtained oligomers are shown in Figure S7 and Figure S8.

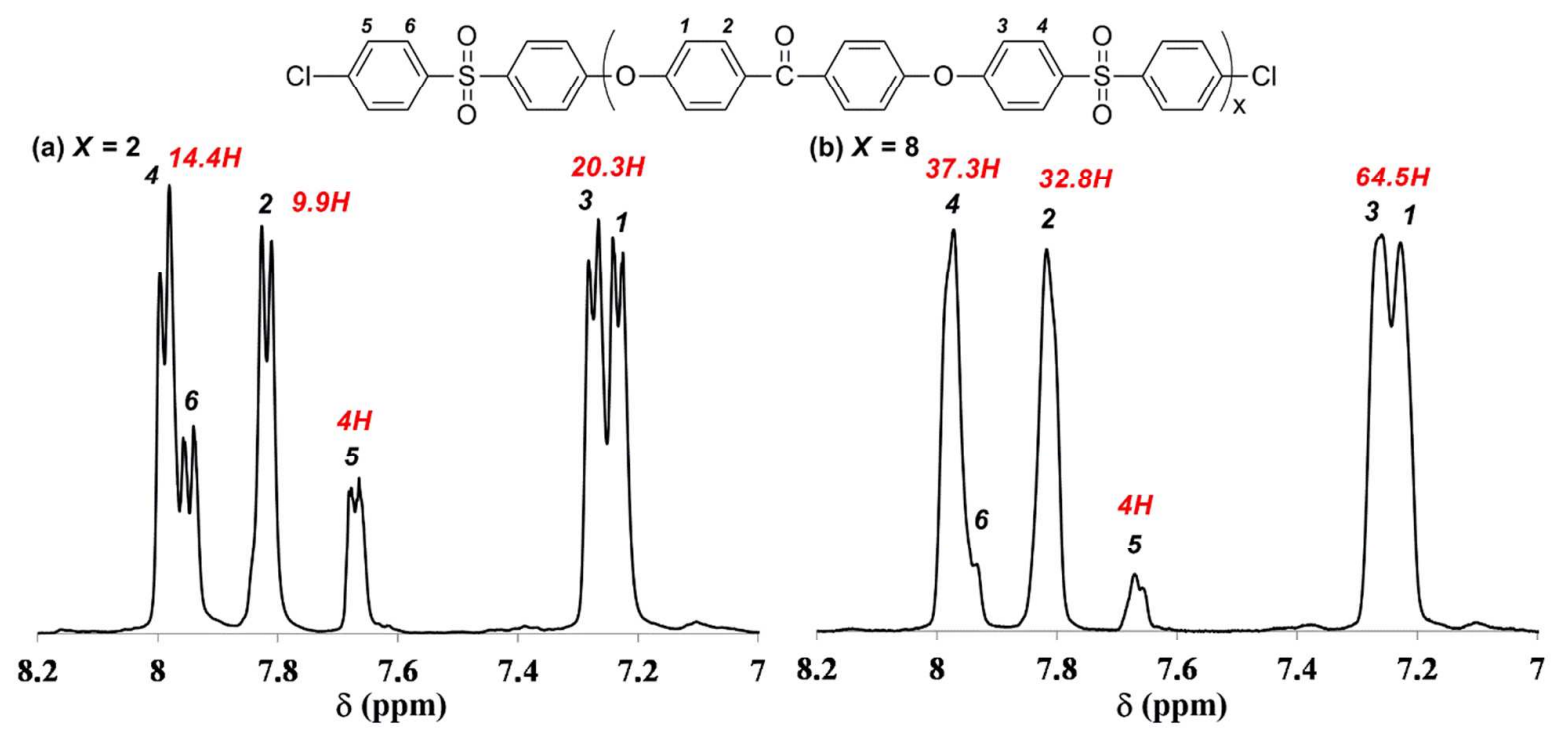

Figure S7. ${ }^{1} \mathrm{H}$ NMR spectra of (a) oligomer $4(X=2)$ and (b) oligomer $4(X=8)$ in DMSO- $d_{6}$ at $80{ }^{\circ} \mathrm{C}$. 


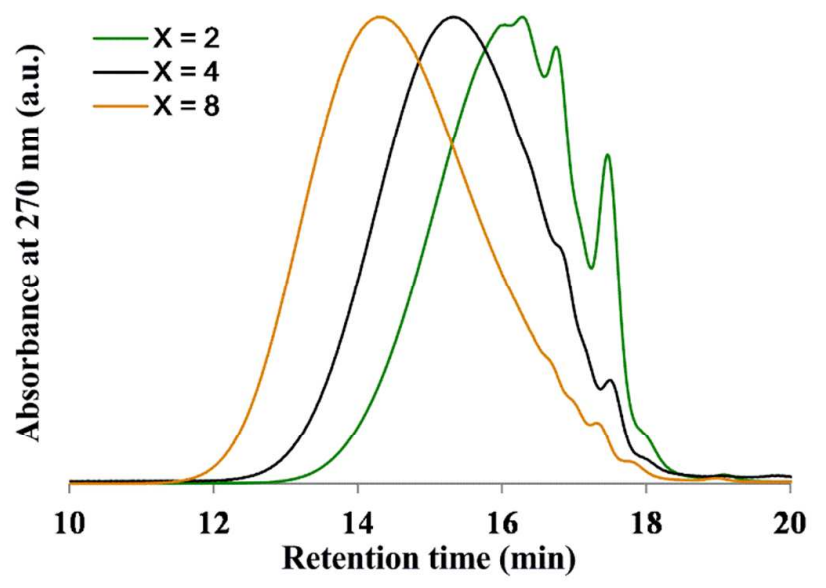

Figure S8. GPC profiles of oligomer 4.

Table S1. Effects of the solvent in Ullmann coupling reaction using $\mathbf{3} \mathbf{a}^{a}$

\begin{tabular}{cccccc}
\hline \multirow{2}{*}{ Solvent } & Yield & \multicolumn{2}{c}{ PE-bl-11(4)a } & $M_{\mathrm{n}}{ }^{d}$ & $M_{\mathrm{w}}{ }^{d}$ \\
\cline { 3 - 4 } & $(\%)$ & $m: n^{b}$ & $m: n^{c}$ & $(\mathrm{kDa})$ & $(\mathrm{kDa})$ \\
\hline DMSO & 80 & $1: 6$ & $1: 2.7$ & 24.7 & 105 \\
DMAc & 70 & $1: 6$ & $1: 3.7$ & 29.4 & 148 \\
\hline
\end{tabular}

${ }^{a}$ Hydrophobic oligomers $4(X=4)$ were used. ${ }^{b}$ Calculated from the feed monomer ratio. $\quad{ }^{c}$ Determined by ${ }^{1} \mathrm{H}$ NMR spectra. ${ }^{d}$ Determined by GPC analyses (calibrated with polystyrene standards).

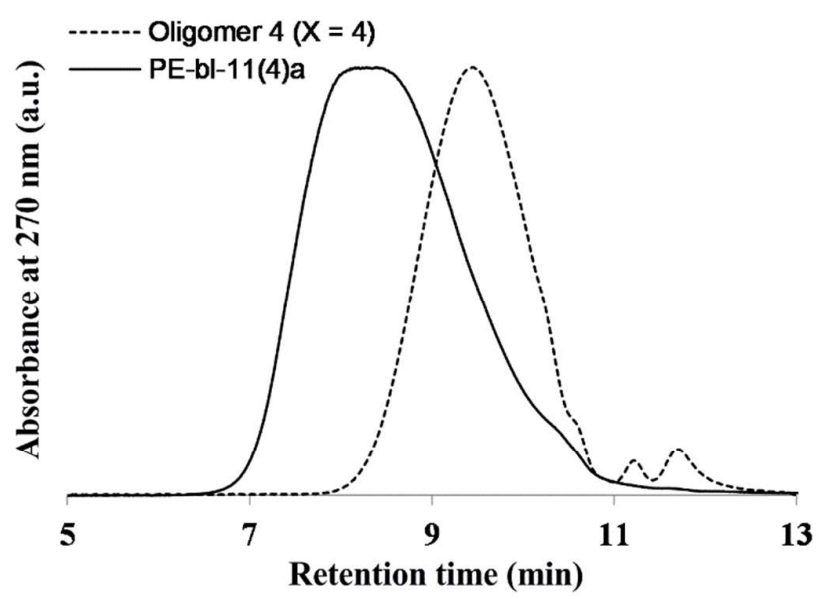

Figure S9. GPC profiles of oligomer 4 and PE-bl-11(4)a ( $m: n=1: 12)$. 


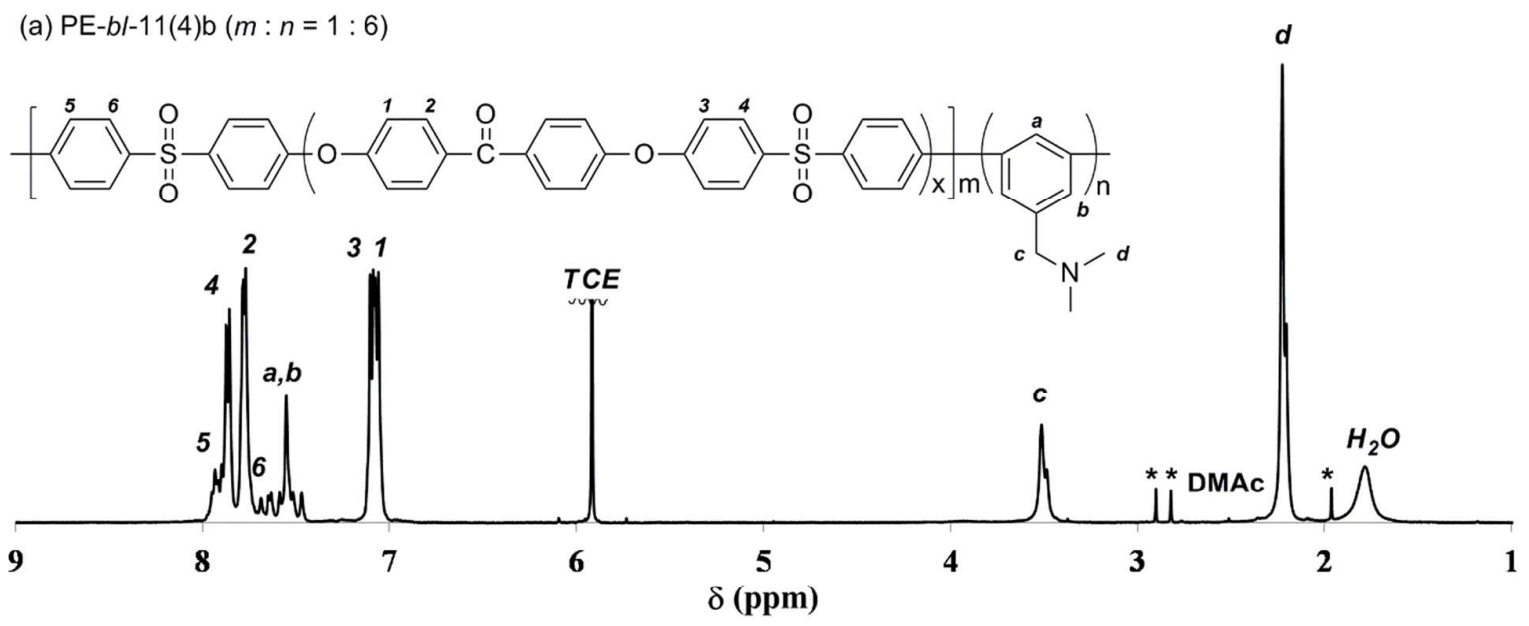

(b) PE-bl-11(4)c $(m: n=1: 6)$
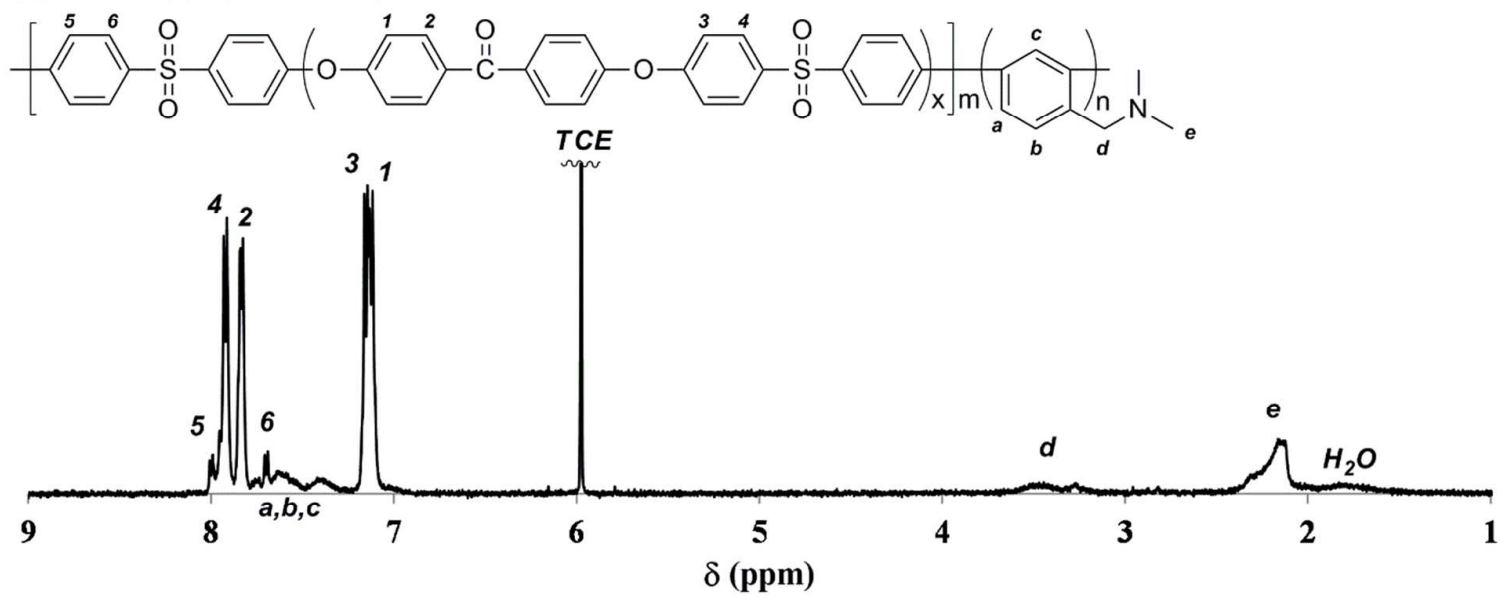

Figure S10. ${ }^{1} \mathrm{H}$ NMR spectra of (a) PE-bl-11(4)b and (b) PE-bl-11(4)c in TCE- $d_{2}$.
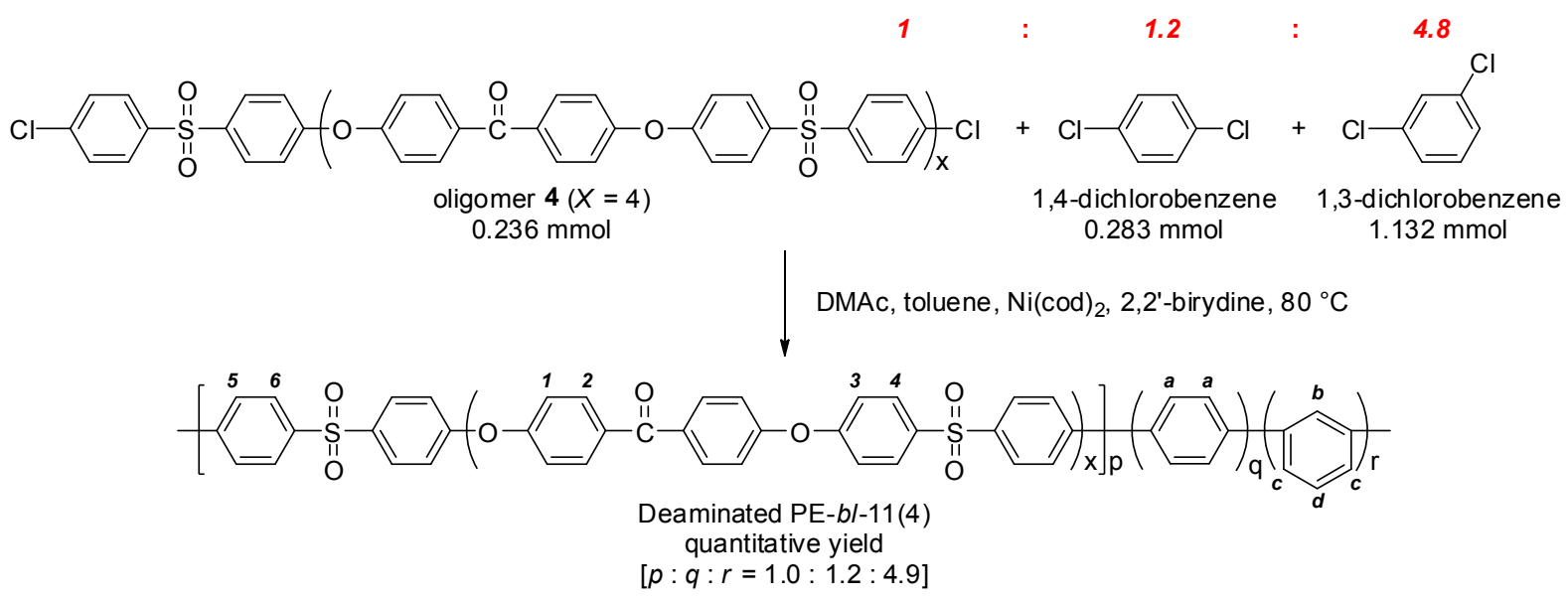

Scheme S1. Ullmann coupling reaction of oligomer 4 and dichlorobenzenes. 
(a)

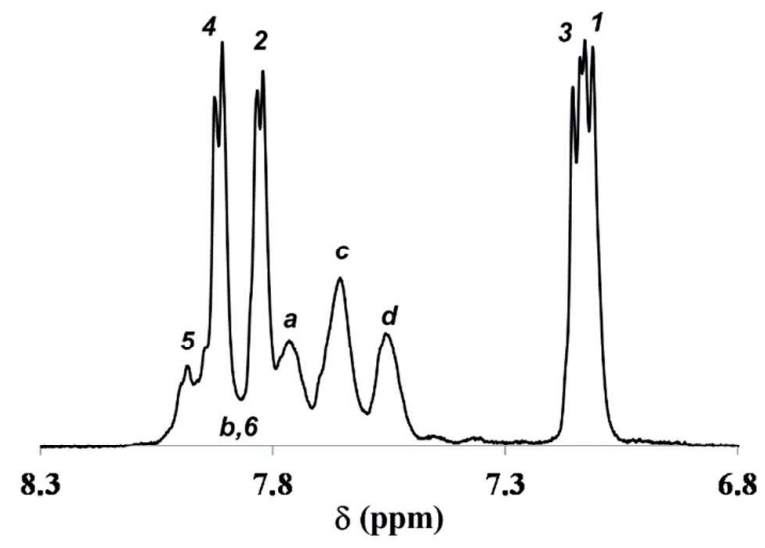

(b)

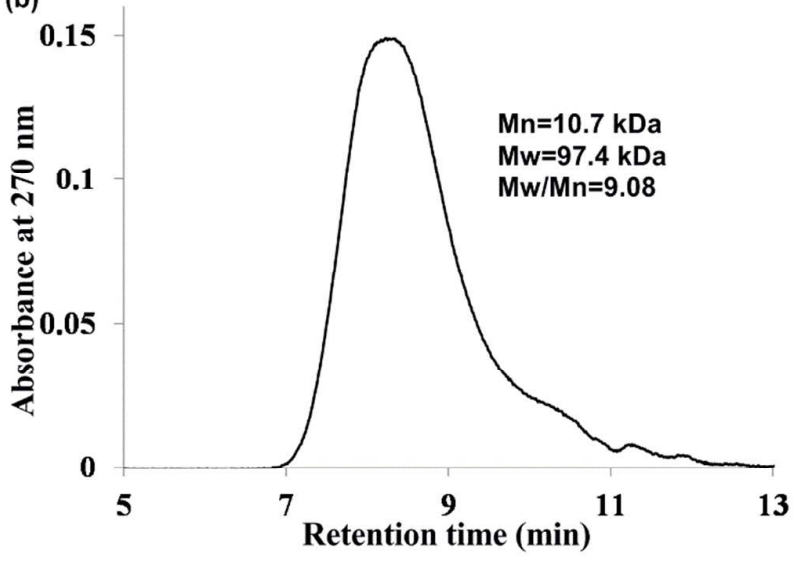

Figure S11. (a) ${ }^{1} \mathrm{H}$ NMR spectrum in TCE- $d_{2}$ and (b) GPC profile of PE- $b l-11(4)$.

Preparation of QPE-bl-11(4)b membrane ( $\boldsymbol{m}: \boldsymbol{n}=\mathbf{1}: \mathbf{6})$. The PE-bl-11(4)b (333 mg, 0.626 mmol; amount of nitrogen) was dissolved in DMAc $(3 \mathrm{~mL})$ and cast onto a flat glass plate. Drying the solution at $50{ }^{\circ} \mathrm{C}$ gave a PE-bl-11 membrane. Then, the membrane was immersed in 5\% (v/v) iodomethane ethanol solution at room temperature for $97 \mathrm{~h}$, washed with ethanol and dried at $80{ }^{\circ} \mathrm{C}$ under reduced pressure overnight to afford a QPE-bl-11(4)b membrane (50-65 $\mu \mathrm{m}$ thick). This membrane was not soluble in DMSO- $d_{6}$ and TCE- $d_{2}$ at all.

Preparation of QPE-bl-11(4)c membrane ( $\boldsymbol{m}: \boldsymbol{n}=\mathbf{1}: \mathbf{6})$. A $20 \mathrm{~mL}$ vial equipped with a magnetic stirrer bar was charged with PE-bl-11(4)c (300 mg, $0.318 \mathrm{mmol}$; amount of nitrogen) and DMAc (3 mL). To this solution, iodomethane $(99 \mu \mathrm{L}, 1.59 \mathrm{mmol})$ was added. After stirring for $48 \mathrm{~h}$, the reaction mixture was directly cast onto a flat glass plate. Drying the solution at $50{ }^{\circ} \mathrm{C}$ gave a QPE- $b l-11(4) \mathrm{c}$ membrane $(90-100 \mu \mathrm{m}$ thick). This membrane could be analyzed by ${ }^{1} \mathrm{H}$ NMR spectrum in DMSO- $d_{6}$ (Figure S12). 

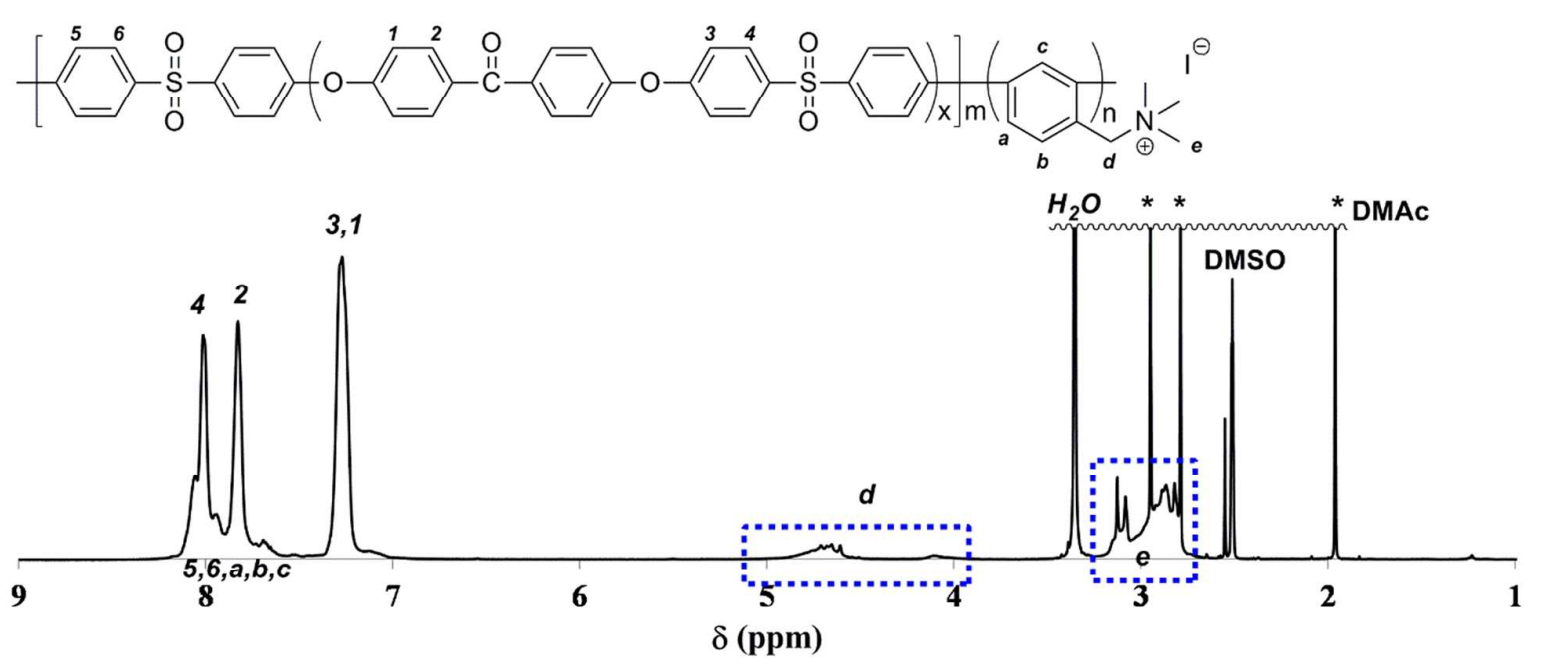

Figure S12. ${ }^{1} \mathrm{H}$ NMR spectra of QPE- $b l-11(4) \mathrm{c}(m: n=1: 6)$ in DMSO- $d_{6}$.

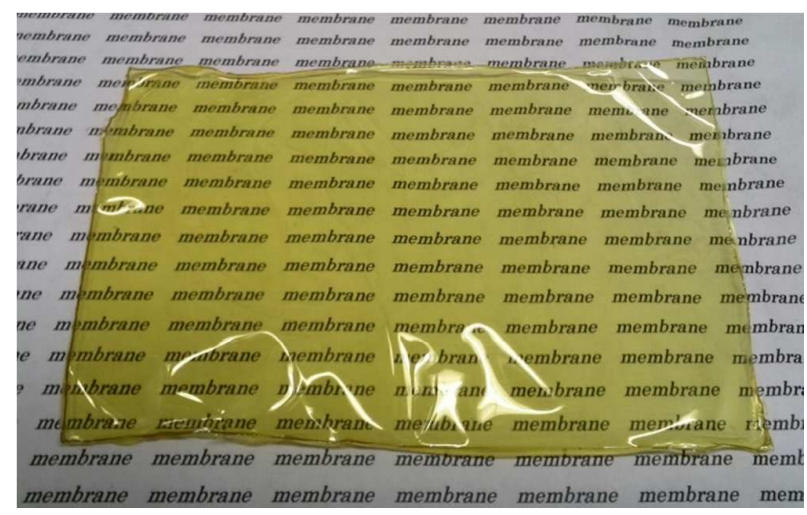

Figure S13. Photo of QPE-bl-11(4)a $(m: n=1: 6)$ membrane (I form).
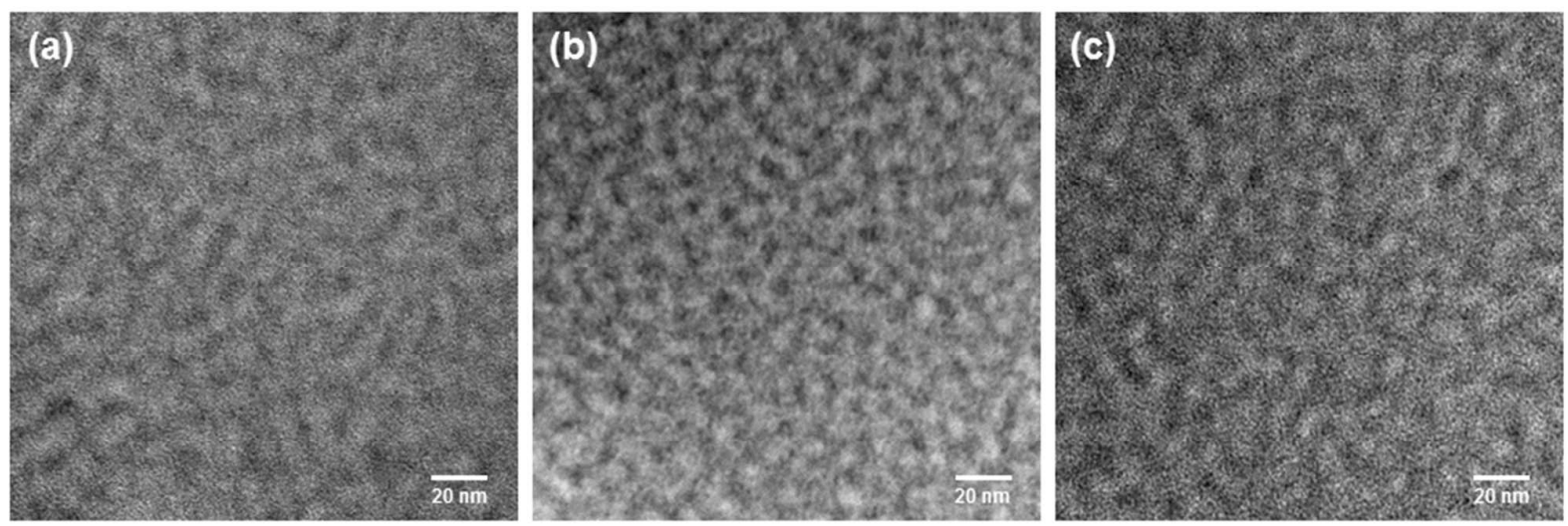

Figure S14. TEM images of (a) QPE-bl-11(4)a $\left(\right.$ IEC $=1.29$ mequiv $\left.\mathrm{g}^{-1}\right)$, (b) QPE-bl-11(4)a (IEC $=1.62$ mequiv $\left.\mathrm{g}^{-1}\right)$, and (c) QPE-bl-11(4)a (IEC $=2.47$ mequiv $\mathrm{g}^{-1}$ ) membranes stained with tetrachloroplatinate ions. 


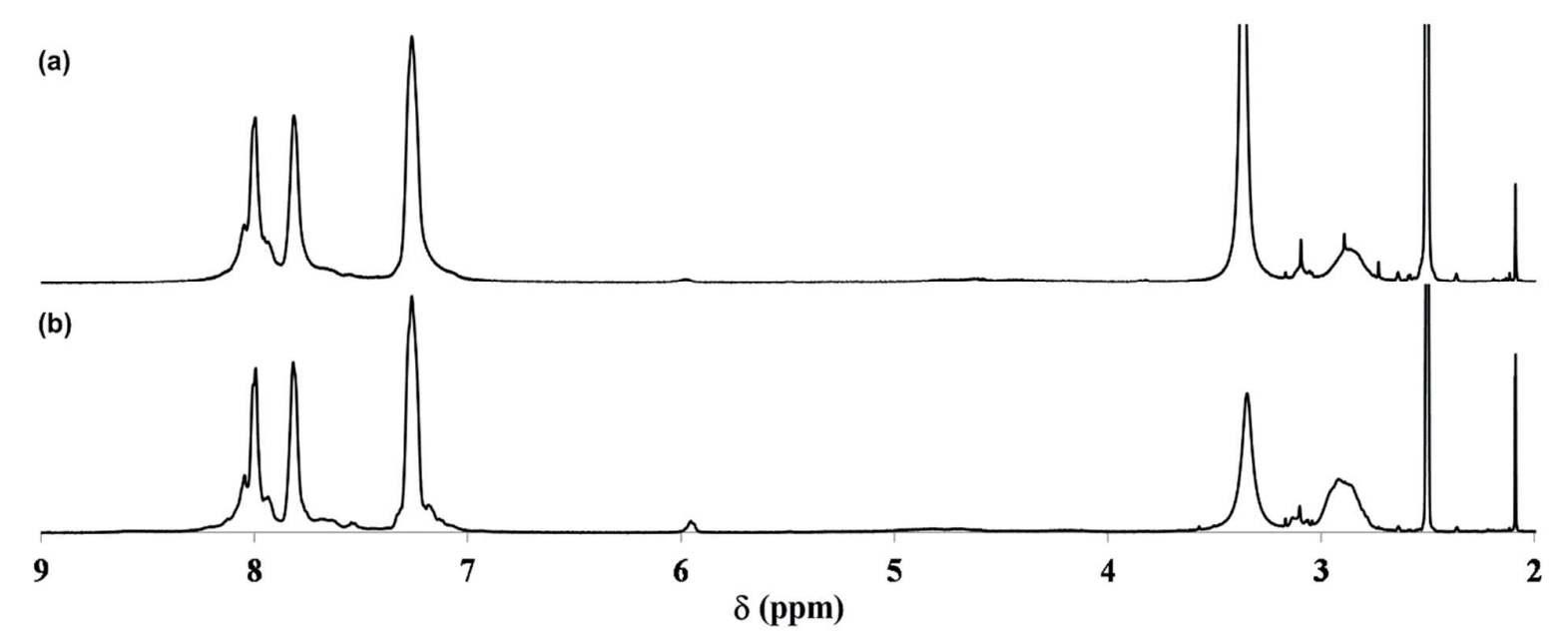

Figure S15. ${ }^{1} \mathrm{H}$ NMR spectra of QPE-bl-11(4)a (IEC $=1.29$ mequiv $\mathrm{g}^{-1}$ ) membranes in DMSO- $d_{6}$ (a) after conductivity measurement and (b) after $1000 \mathrm{~h}$ stability test in $1 \mathrm{M} \mathrm{KOH}$ at $60{ }^{\circ} \mathrm{C}$.

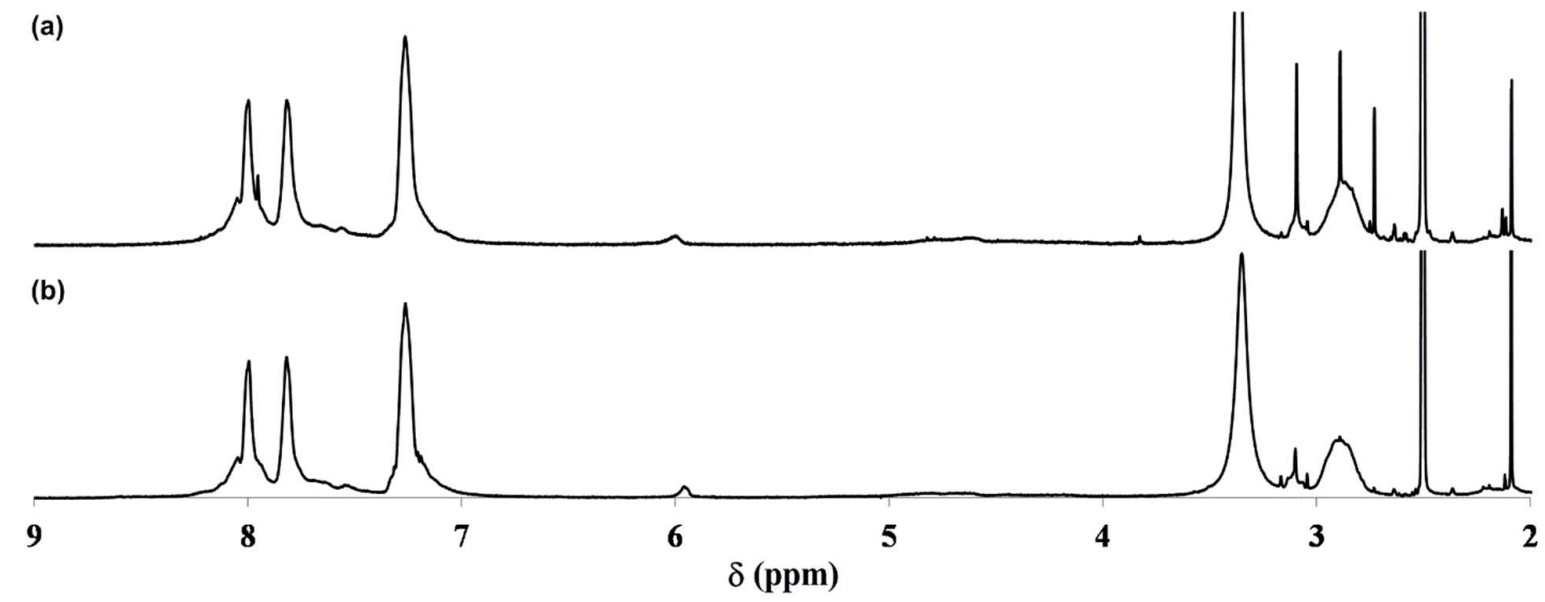

Figure S16. ${ }^{1} \mathrm{H}$ NMR spectra of QPE-bl-11(4)a (IEC $=1.62$ mequiv $\left.\mathrm{g}^{-1}\right)$ membranes in DMSO- $d_{6}$ (a) after conductivity measurement and (b) after $1000 \mathrm{~h}$ stability test in $1 \mathrm{M} \mathrm{KOH}$ at $60^{\circ} \mathrm{C}$.

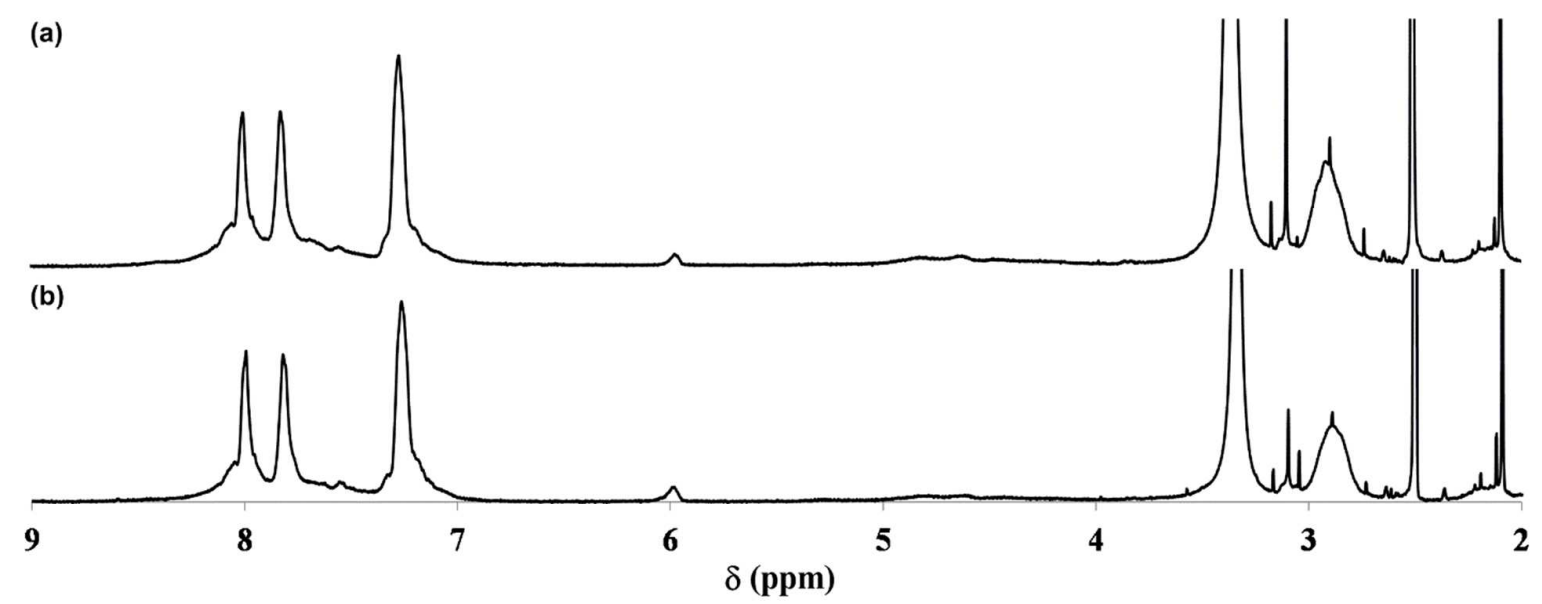

Figure S17. ${ }^{1} \mathrm{H}$ NMR spectra of QPE-bl-11(4)a (IEC $=2.47$ mequiv $\left.\mathrm{g}^{-1}\right)$ membranes in DMSO- $d_{6}$ (a) after conductivity measurement and (b) after $1000 \mathrm{~h}$ stability test in $1 \mathrm{M} \mathrm{KOH}$ at $60{ }^{\circ} \mathrm{C}$ 

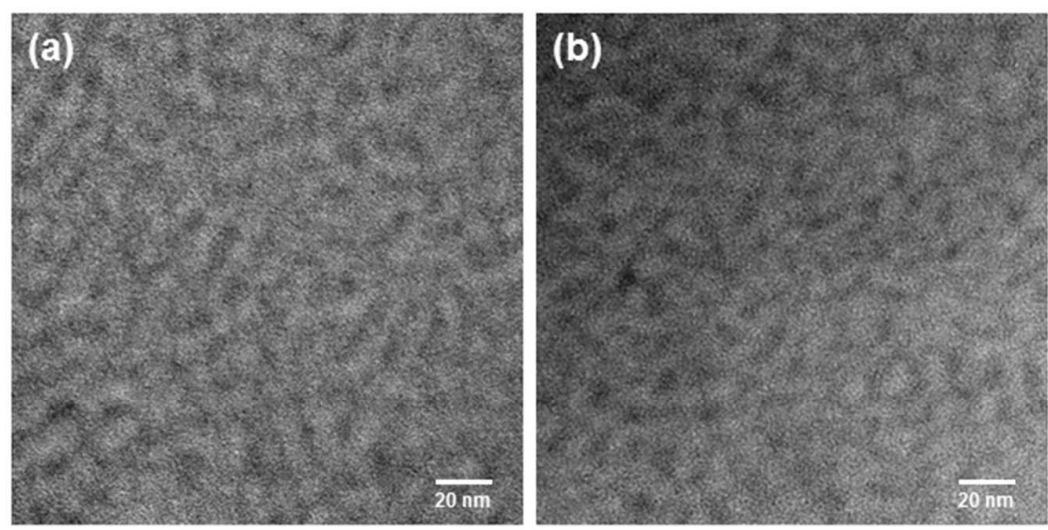

Figure S18. TEM images of QPE-bl-11(4)a (IEC $=1.29$ mequiv $\mathrm{g}^{-1}$ ) membranes (a) before and (b) after 1000 h stability test in $1 \mathrm{M} \mathrm{KOH}$ at $60{ }^{\circ} \mathrm{C}$.

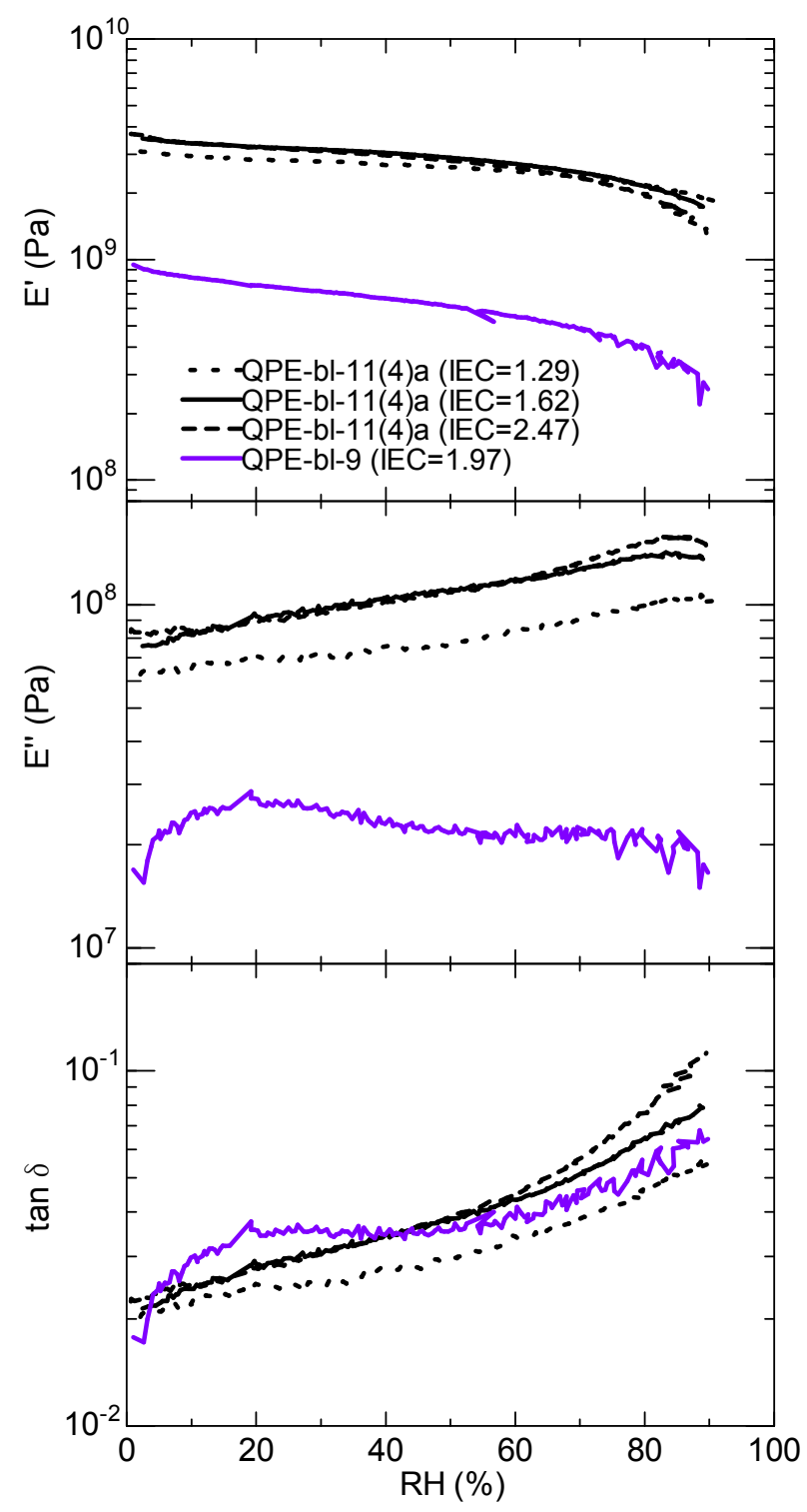

Figure S19. DMA of QPE-bl-11(4)a (IEC $=1.29,1.62$ and 2.47 mequiv $\left.\mathrm{g}^{-1}\right)$ and QPE-bl-9 $($ IEC $=1.97$ mequiv $\mathrm{g}^{-1}$ ) membranes at $80{ }^{\circ} \mathrm{C}$ as a function of $\mathrm{RH}$. 